\title{
RISK CATEGORIES OF BASEL II AND APPLICATIONS OF OPERATIONAL RISK IN BANKS
}

\author{
DOI: 10.17261/Pressacademia.2019.1107 \\ PAP- V.9-2019(54)-p.295-298
}

\section{Nihan Efsun Atesoglu ${ }^{1}$, Yurdagul Meral ${ }^{2}$}

${ }^{1}$ Citibank Foreign Operations Despartment, i̇stanbul, Turkey. nihan atesoglu@hotmail.com , ORCID: 0000-0003-2562-8198

${ }^{2}$ istanbul Medipol University, Beykoz, İstanbul ymeral@medipol.edu.tr, ORCID: 0000-0001-9244-1994

To cite this document

Atesoglulu, N.E., Meral, Y., (2019). Risk categories of BASEL II and applictions of operational risk in banks. PressAcademia Procedia (PAP), V.9, p.295-298

Permanent link to this document: $\underline{\text { http://doi.org/10.17261/Pressacademia.2019.1107 }}$

Copyright: Published by PressAcademia and limited licenced re-use rights only.

\section{ABSTRACT}

Purpose- The new regulation "The New Basel Capital Accord" which has been created in order to eliminate the shortcomings of Basel I, in 1999, Basel II, aimed to modify each bank's own criteria, regulatory activities and preferences, according the banks' own terms and practices. Basel II standards also are criticised as well like Basel I. The most critical aspect of Basel II was its standards to many issues and their difficulties in realization. With the criticism to Basel II and the emergence of the crisis, in 2010, Basel III regulations came into effect with its innovative standards such as strengthening capital, liquidity coverage ratio, and restrictions to leverage ratios. The aim of this study is to examine 'operational risk' and application of operational risk in banks as given in Basel II.

Methodology- In this study, Basel II New Capital Accord risk categories within three pillars and the effects of Basel II regulation on operational risk are investigated.

Findings- Definition of operational risk, processes of risk measurement and management, operational losses

Conclusion- Audit of information systems, CobIT processes and methods

Keywords: Basel I, Basel II, Base III, economic crisis, risk management, capital edequecy, operational risk, IT risks, CobIT in banks JEL Codes: H12, G32, M15, F13, G28, G38

\section{BASEL II RISK KATEGORILERI VE OPERASYONEL RISKIN BANKALARDA UYGULANMASI}

\section{ÖZET}

Amaç- Basel I'in eksikliklerini gidermek amacıyla 1999'da "Yeni Basel Sermaye Yeterliliği Uzlaşısı” olarak tanımlanan yeni kurallar, Basel l'in aksine, her bankanın kendi kriterlerini, düzenleme çalışmalarını ve tercihlerini, yine o banka şart ve uygulamalarına göre belirleyebilmelerini amaçlamıştır. Basel I uygulamalarında olduğu gibi Basel II uygulamaları da eleştirilere maruz kalmış, en çok eleştiri alan yönü ise uzlaşıda çok fazla sayıdaki konulara getirilen standartlar ve bunların gerçekleştirilme güçlüğü olarak belirlenmiştir. Getirilen eleştiriler ve krizin de ortaya çıkmasıyla 2010 yılında Basel II'nin yerini, likidite karşılama oranı, kaldıraç oranlarına getirilen sınırlama ve sermayenin güçlendirilmesine yönelik yeniliklere yer veren Basel III düzenlemeleri almıştır. Bu çalışmanın amacı Basel II'de tanımlanan 'operasyonel risk' kavramı ve bankalarda operasyonel riskin uygulanmasını incelemektir.

Method- Bu çalışmada Basel II Uzlaşısı uygulamalarının operasyonel risk açısından etkileri üzerinde durulmuştur.

Bulgular- Operasyonel riskin tanımı, risk ölçüm ve yönetim süreçleri, operasyonel kayıp türleri

Sonuç- Bilgi sistemlerinin denetimi, CobIT süreçleri ve uygulama metotları, ilgili tebliğ ve yönetmelikleri

Anahtar Kelimeler: Basel I, Bael II, Basel III, ekonomik kriz, risk yönetimi, sermaye yeterliliği, operasyonel risk, BT riskleri, bankalarda CobIT JEL Kodları: H12, G32, M15, F13, G28, G38

*Bu çalışmada, Nihan Efsun Ateşoğlu’nun, Okan Üniversitesi, Sosyal Bilimler Enstitüsü, 01.03.2013 tarihli, “Basel II Risk Kategorileri ve Operasyonel Riskin Bankalarda Uygulanması" adlı projesi esas alınmıştır 


\section{Giriş}

Uluslararası Ödemeler Bankası (BIS) altında kurulan Basel Komitesi (Basel Bankacılık Düzenleme ve Denetleme Komitesi) bankaların denetim, gözetim ve sermaye yeterliliği konularında kontrolünü sağlayarak uluslararası standartlarda çalışmalarını sağlamaktır. 1988 yılında "Basel Sermaye Uzlaşısı" yani Basel I standartını yayımlayan komitenin bu standarttaki amacı banka sermayesinin toplam miktarı üzerinde durarak bankaların karşılaşabilecekleri ekonomik krizlere ve risk gruplarına karşın minimum sermaye gereksinimlerini bulundurmalarını sağlamaktır. Sadece asgari sermaye yeterliliğinin sağlanarak bankaların finansal sistemlerini sağlamlaştıramadıkları görüldükten sonra birçok konuda yetersiz olduğu anlaşılan ve eleştirilen bu düzenlemenin yerini 1999 yılında risk duyarlılığı daha yüksek olan Basel II (Yeni Sermaye Uzlaşısı) düzenlemeleri almışır. Basel II standartları Basel I'de yer alan minimum sermaye yeterliliği kuralına ek olarak denetim otoritesi ve piyasa disiplini etkenlerini de dahil etmiştir. Böylece Basel II Sermaye Uzlaşısı kredi riski, piyasa riski ve operasyonel riskin de dahil olduğu sermaye yeterliliği, denetim otoritesinin gözden geçirmesi ve piyasa disiplini olmak üzere üç yapısal bloğu kapsamına almıştır. Basel II standartları küresel kriz döneminde beklentileri karşılayamayınca birçok eleştiriyi beraberinde getirmiştir. Küresel krizin nedenleri arasında görülen likidite sıkıntıları ve kaldıraç oranları konusunda yetersiz kaldığı düşünülen Basel II uygulamalarının yerini 2010 yılında kabul edilen Basel III kriterleri almışıı. Basel III ile gelen yenilikler; likidite karşılama oranı, kaldıraç oranlarına getirilen sınırlama ve sermayenin güçlendirilmesine yönelik çalışmalar olarak görülmektedir. Basel IV ile operasyonel riskin belirlenmesinde standart uygulamalar belirlenmiştir.

\section{LITERATÜR INCELEMESi}

\subsection{Uluslararası Ödemeler Bankası (BIS-Bank of International Settlements)}

Uluslararası Ödemeler Bankası (BIS), Birinci Dünya Savaşı sonrasında Versailles Antlaşması çerçevesinde Almanya'nın ödeyeceği tazminat ödemelerini yönetmek amacıyla 1930 yılında İsviçre'nin Basel şehrinde kurulmuştur. 1974 yılında Almanya'daki Herstatt Bank'ın ve Amerika'daki Franklin National Bank'ın iflası, G- 10 ülkeleri merkez bankalarının bankacılık denetimini sağlayacak olan Basel Komitesi'nin kurulmasına neden olmuştur. Komite 1988 yılında, küresel standartlar seviyesinde uluslararası faaliyet gösteren bankalar için kredi risk ölçümünü tanıtan Basel Sermaye Uzlaşısı'nı yayınlamıştır. Bankaların denetim otoritelerinin ve merkez bankalarının üst düzey yönetiminden oluşan komitenin amacı bankaların ortak bir standartta çalışmasını sağlamak ve sadece ülkelerin kendi içinde kalmayıp, global olarak yayılan muhtemel bir ekonomik krize karşı önlem almak ve bankaların sermaye dayanıkııı̆ı̆ını artıırmaktır. Basel standartları, uluslararası alanda faaliyet gösteren bankaların maruz kaldığı çeşitli risklerin daha iyi ve şeffaf bir şekilde ölçülmesini, kriz durumlarında bu risklerin artma olasılı̆ının sınırlanmasını ve küresel mali altyapının güçlendirilmesini amaçlamaktadır (BIS, 2019).

\subsection{Basel I}

1988 Basel Uzlaşısı olarak da bilinen Basel I, bankalar için asgari sermaye gereksinimlerine ilişkin olarak İsviçre'deki Basel Bankacılık Denetim Komitesi (BCBS) tarafından yayınlanan standartlar bütünüdür. Sermaye Uzlaşısı (Basel I) özellikle kredi riskinin önemini vurgulayan ve bankaların krizlere karşı dayanıklılı̆ını artırmak için sermayelerinin riskli aktiflere oranının \% 8'den az olamayacağını öngören kredi riski ölçüm sistemidir (Aykut, 2008). Bu sistemle, bankalarda finansal sağlamlığın artııııması ve bankaların yeterli sermayeyi bünyelerinde barındırarak her türlü riskin kontrol edilmesi amaçlanmış, asgari sermaye oranı bu finansal sağlamlığın oluşturulması için bir kriter haline gelmiștir. Böylece yeni sermaye yeterliliği uzlaşısılla birlikte her ülke kendi ulusal kriterleri ile düzenleme çalışmalarını ve tercihlerini kendi banka şart ve uygulamalarına göre belirleyebileceklerdir.

\subsection{Basel II}

Basel II içeriğine, Basel I düzenlemelerinde yer almayan bazı risk grupları da eklenmiş, sermaye yeterliliği tanımı yeniden düzenlenerek bankaların bulundurmaları gereken minimum sermaye seviyeleri konusunda uzlaşılmış, bankaların karşılaşılan risklere duyarlıığı yeniden ölçülmüş ve düzenleme kapsamlı bir nitelik kazanmıştır. Basel II, daha hassas risk ölçümü, her bir bankaya özel risk profilinin, o bankaya özel olarak ayrı ayrı belirlenmesi, ayrıca üst yönetim sorumluluklarının arttırılması ve finansal tabloların ise gerçek durumun yansıtılacak şekilde açıklanması zorunluluğu ile sektörde asimetrik bilgilerin azaltılarak, daha sağlam ve rekabetçi ve aynı zamanda istikrarlı bir sektör hedeflenmektedir (Yayla, Kaya, 2005). Basel II, zorunlu özkaynak intiyaçları ile riskler eşleştirilmiş, daha geniş kapsamlı bir yaklaşım ile risk ölçümü ve yönetimdeki gelişmeleri kapsayarak, sistem güvenliğini destekleyerek, rekabet eşitliğini kolaştırarak, karmaşık olmayan, daha sade düzeyli uluslararası bankalara odaklanmıştır (Demir, F. et al, 2008).

\subsection{Basel III}

Yaşanan global krizin ardından daha önce geliştirilmiş ve uygulanmış Basel II uzlaşısının da yetersiz kaldığı görülmüş ve eksiklikleri gidermek, yeni yaklaşımlar ve tedbirler ortaya atmak, böylece yaşanabilecek krizleri engelleyebilmeye çalışmak ya da zararı en aza indirgemek amacıyla Basel Komitesince Basel III uzlaşısı hazırlanmıştır (Demir, Gürel, 2012). Basel III standartları ile global kriz nedenleri arasında olan kaldıraç oranları ve likidite sıkıntıları yeni bir düzenlemeye giderek, sermayenin nicelik ve niteliksel arttııılması, likidite risk ölçümü ve kaldıraç oranları sınırlamaları çalışmalarının eklenmesi sağlanmıştır. Basel III uzlaşısının nedenleri, olumsuz piyasa koşullarında ani düşüş gösterebilen sermaye tamponlarının güçlendirilmesi, banka sermayelerinin kalitesinin artırıması, Basel II’ye destek olmak üzere bir kaldıraç oranı uygulamasının getirilmesi, asgari sermaye gereksinimindeki döngüselliği azaltma ve karşılık ayrılması, bankacılık sektörünün kuvvetlendirilmesi amacıyla ortaya koyduğu sermaye ve likidite düzenleme önerileri sunması, risk yönetiminin geliştirilmesine ek olarak, bankaların stres ortamlarına karşı dayanıklıı̆ı̆ının artııııması (BDDK, 2010).

\subsection{Basel IV}

2020'de tümüyle uygulamaya girmesi beklenen Basel IV, operasyonel risk için standart bir yaklaşım getirmektedir. Türkiye Bankalar Birliğinin (Bankalar Birliği, 2016), Basel IV ile ilgili bilgilendirme toplantısına göre operasyonel risk için uygulanan tüm yöntemlerin, standart bir yöntemle değişmesini öngörülmektedir. Tüm iş ve faaliyet göstergelerinin uygulanması ile operasyonel riske duyarlılığın arttırııması ve 
operasyonel risk yönetiminin geliştirilmesi hedeflenmektedir. Standart yöntem ile daha önceki karmaşıklığın ve risk ağırlıklı tutar hesaplanmasında değişkenliği azaltılabilmesi planlanmıştır.

\section{OPERASYONEL RISK}

Operasyonel riskin tanımı BDDK'nın ilgili yönetmeliğinde “Banka içi kontrollerdeki aksamalar sonucu hata ve usulsüzlüklerin gözden kaçmasından, banka yönetimi ve personeli tarafından zaman ve koşullara uygun hareket edilmemesinden, banka yönetimindeki hatalardan, bilgi teknolojisi sistemlerindeki hata ve aksamalar ile deprem, yangın, sel gibi felaketlerden veya terör saldırılarından kaynaklanabilecek zarar olasılığı" olarak tanımlanırken, Basel II'de "Yetersiz ve başarısız içsel süreçlerden, personel ve sistemlerden ya da dışsal olaylardan kaynaklanan, doğrudan veya dolaylı zarar riski" (Varlı, 2006) olarak tanımlanır. Operasyonel risk kaybı, zorunlu sermayenin yaklaşık yüzde 20 'sini oluşturacağı beklenmektedir (TBB, 2002).

Basel II'de operasyonel riske esas tutarın, sermaye yeterliliği rasyosuna dahil edilmesiyle, operasyonel riskin önemi daha da artmıştır. Basel düzenlemelerince bankaların yasal sermaye gerektiren küçük risklerden çok beklenmedik, birinci derecede önem taşıyan operasyonel riskler konusunda gerekli denetimin sağlanarak önlemler alınması belirtilmiş ve bu düzeydeki riskler için ayrı bir ekonomik sermaye bulundurmaları gerekliliği gündeme gelmiştir. Risk yönetim sisteminin oluşturulması ve bankalarda operasyonel riskin tanımlanabilmesi için öncelikle risk kayıp olaylarını belirlemek ön koşul olarak görülmektedir.

British Bankers Association operasyonel riskleri 1. ve 2. seviye olarak kategorize etmiş, operasyonel riske konu olan örnekleri de ayrıca belirtmiştir. Buna göre; 1. seviyede süreçlerden kaynaklanan, insanlardan kaynaklanan, sistemlerden kaynaklanan ve harici(dışsal) etkenlerden kaynaklanan riskler belirtilmekte; 2. seviyede bu riskleri oluşturan genel süreçler sınıflandırılmakta, faaliyet örneklerinde ise sınıflandırılan operasyonel risklere neden olan ana kaynaklara işaret edilmektedir. Operasyonel Risk Yönetimi uygulamalarında risk değerlendirmesi yapılırken önem verilmesi gereken alanlar belirlenmiş, uygulamanın kapsamlı olması için faaliyet örnekleri de tanımlanarak tam içerikli Operasyonel Risk Yönetimi oluşturulmuştur. Bankalar, piyasa riski ile ilgili operasyonel risk kayıpları, operasyonel risk olarak dikkate alarak, bunlar için de operasyonel risk sermayesi hesaplayacaklardır (BDDK, 2005).

\section{CobIT ve BILGi SISTEMLERI DENETIMi}

CobIT (Control Objectives for Information and Related Technologies/Bilgi ve İlgili Teknolojiler için Kontrol Hedefleri), günümüzdeki başlıca yayımcısı ISACA (Information Systems Audit and Control Association/Bilgi Sistemleri Denetim ve Kontrol Birliği) ve ITGI (IT Governance Institute/Bilişim Teknolojileri Yönetişim Enstitüsü) tarafından 1996 yılında geliştirilmiştir. CoblT, bilgi ve ilgili teknoloji için kontrol amaçları yaklaşımıdır ve ulaşılmak istenen kontrol amaçları ve bu amaçlara ulaşmak için gerekli yollar tarafından tasarlanan kontroller olarak tanımlanan iç kontrol odaklı bir yaklaşımdır (Uzunay, 2007). Temel olarak bu problemi adresleyen ve yaygın kabul gören BT yönetişim çerçevesi CobIT olarak görülmektedir (Deloitte, 2013).

\section{SONUÇ VE ÖNERILER}

Sonuç olarak, faaliyetleri boyunca her adımda büyük risklerle karşı karşıya olan finans sektörünün bunlarla baş edebilmek için zaman geçtikçe ve ürünler daha karmaşık hale geldikçe çeşitli arayışlar içerisine girmiş olduğunu söyleyebiliriz. Basel I, Basel II ve son olarak da Basel III direktifleri gözden geçirildiğinde her şeyin temelinde güçlü sermaye tabanı olması esas alınmıştır. Özellikle aracılık işlemlerinden daha çok, parayı doğrudan risk eden ürünlerle yaşayan ve büyüyen, bu süreçte de birçok risklerle bir arada yaşamakta olan bankacılık sektörü, emniyet olarak güçlü sermaye yapısını öngörmüştür. Bunu sağlayacak yöntem olarak sermaye yeterliliği hesaplarında ince hesaplar yapmakta, çok dikkatli adımlar atmaya çalışmaktadır. Zaten dünyanın her yerinde yasal otoriteler de finansal sektörde istikrar sağlamak için bu hesaplamaları detaylı raporlama yöntemleriyle titiz bir şekilde izlemekte, çeşitli yaptırımlar uygulamaktadırlar. Bu bağlamda, en temel riskler gibi görünen Piyasa ve Kredi risklerinin yaratabileceği sıkıntıların finansal kuruluşun geleceğini tehdit etmemesi için de her türlü önlemin alınması için çeşitli yasal düzenlemeler yapılmaktadır. Bu durum finansal ürünler var oldukça ve el değiştirmeye devam ettikçe karşımıza çıkacak bir süreçtir.

Ancak göz önünde bulundurulması gereken çok önemli diğer bir nokta daha vardır; operasyonel riskler. Yasal yaptırımlar, çeşitli rasyo ve oranlar ne kadar düzenleyici ve kısıtlayıcı olursa olsun, finansal kuruluşlar bunlara ne kadar uyarsa uysun, işlemler gerçekleştirilirken yaşanabilecek çok sayıda başka riskler mevcuttur. Kimisi masum, kimisi kötü niyetli nedenlere dayanan bu riskleri önceden belirleyip bunlara karşı tedbirler almayan finansal kuruluşların geleceği belirsiz olacaktır. Bunu sağlamak için her kuruluş kendi risklerinin analizini yapıp kuruluşa özgü bir "Risk Haritası" oluşturmalıdır. Özellikle operasyonel risklere karşı ne kadar hassas ve kırılgan olduklarını ölçmeli, daha bu riskleri yaşamadan, alınması gereken tedbirlerini almalıdır. Bunun için de karşı karşıya oldukları risklerini ve bunların yaratabileceği hasarları çok iyi bilmelidir. Finansal kuruluşların karşı karşıya kalabileceği en ciddi operasyonel riskler doğal afetler ve savaş gibi kendi kontrolümüz altında olmayan riskler hariç tutulursa, büyük ölçüde "insan" ve "teknolojik" nedenlere dayanmaktadır. Finansal kuruluşların yönetim ve gözetim organları operasyonel riskler için hep bu iki faktöre önem vermiştir. Kuruluş yöneticileri bu faktörleri tehlike halinden çıkarıp, faaliyetlerini sürdürmekte en etkili silahları haline getirdikleri takdirde başarılı bir "Risk Yönetimi" sistemi oluşturabilmişler demektir. Zaten risk yönetimi sistemlerini de insanlar kurduğuna göre, bu iki faktörün finansal kuruluşun risklerle baş etmesini sağlayacak en önemli silahlar haline getirilmesini oluşturan mekanizmalar yine insanlar olacaktır, yani yöneticiler. Elindeki bu iki silah ya kendilerini imha edebilecek tehlikedir ya da faaliyetlerini güvenli bir şekilde yürütmelerine yardımcı olacak en güçlü yardımcılarıdır. Her şey kurulmuş olan Risk Yönetimi Sistemine ve bunların işletilmesine bağlıdır.

Bankalar gibi karmaşık ve birden çok katmandan oluşan yetkilendirme seviyesine sahip kurumlarda, kullanıcı tanımlama ve yetkilendirme faaliyetlerinin kurum içinde dağınık bir yapıda bulunması, operasyonel yükü arttırmakla birlikte operasyonel riskleri de kabul edilebilir seviyelerin üstüne taşıyabilmektedir. Hangi kullanıcı gruplarında hangi yetkilerin olması gerektiği (kullanıcı-rol-profil), acil veya beklenmedik durumlara karşı bir yekilendirme prosedürünün bulunması ve işletilebilmesi sadece yönetimsel bir konu olmayıp, operasyonel risk yönetimi sürecinde önceden tanımlanmış ve ölçümlenebilen süreçler olarak yerini almalıdır. ABD’nin en büyük Bankalarından JP Morgan Chase and Co.'nun "Londra Balinası" olarak anılan simsarı (trader) Bruno Michel Iksir'in yapmış olduğu bir CDS (Credit Default Swap) al-sat işlemi 
(hedging) sonucu bankayı tek başına 2 Milyar dolardan fazla zarara uğratabilmesini veya işviçre'nin en büyük bankası olan UBS'in bir çalışanı tarafından yapılan yetkisiz alım-satım işlemleri nedeniyle 2 milyar dolar kayba uğraması kötü yönetilen operasyonel risk yönetimi süreçlerine örnek olarak gösterilebilir.

\section{KAYNAKÇA}

Aykut, C. (2008). "Basel II Standartları", Türkiye Cumhuriyeti Dışişleri Bakanlığı Yayınları: Uluslararası Ekonomik Sorunlar Dergisi, Ağustos, Sayı: 30, http://www.mfa.gov.tr/data/Kutuphane/yayinlar/EkonomikSorunlarDergisi/sayi30/basel.pdf .

Bankacilık Düzenleme ve Denetleme Kurumu. (2005). 10 SORUDA YENI BASEL SERMAYE UZLAŞISI (BASEL-II).

https://www.bddk.org.tr/ContentBddk/dokuman/duyuru basel 0001 38.pdf.

BDDK. (2010). Piyasa Riski Ölçümleme Yöntemlerine ilişkin Analiz, Ankara, Nisan 2010: 2

Deloitte, COBIT ve Proje Yönetimi Bütünleşimi, (t.y) http://www.denetimnet.net/Pages/COBITveProje Yonetimi.aspx.

Faruk Demir, Bilal Soysal, Emre Per, Ramazan Karaşahin, Ayhan Küçük, Emine Karataş, Mehmet Sarı, Rıza Tan: Bankaclık Düzenleme ve Denetleme Kurumunun 1 Ocak 2008 tarihli Çalışma Tebliği, CRD/Basel - 2 Ülke Uygulamaları.

Türkiye Bankalar Birliği. (2002). Basel Komite Yeni Sermaye Yeterliliği Düzenlemesi.

https://www.tbb.org.tr/Dosyalar/Arastirma_ve_Raporlar/Basel.doc

Türkiye Bankalar Birliği. (2016). Basel IV: Bankaları Bekleyen Zorluklar. https://www.tbb.org.tr/Content/.../Basel IV TBB\&EY Sunumu.pdf).

Uzunay, Vildan, "COBIT (Control Objectives for Information and Related Technology)", COBIT, 2007: 3-4

Varlı, A.T. “Basel II- Operasyonel Risk”, Bilgi Sistemleri Denetiminde BDDK Yaklaşımı, 19-22 Nisan 2006: 14.

Yayla, M. ve Kaya, Y.T, (2005), Basel-II, Ekonomik Yansımaları ve Geçiş Süreci, BDDK, ARD Çalışma Raporları, No:2005/3 